\title{
Game Mechanics on Social Live Streaming Service Websites
}

\author{
Katrin Scheibe \\ Dept. of Information Science \\ Heinrich Heine University, Düsseldorf \\ katrin.scheibe@hhu.de
}

\author{
Franziska Zimmer \\ Dept. of Information Science \\ Heinrich Heine University, Düsseldorf \\ franziska.zimmer@hhu.de
}

\begin{abstract}
Social live streaming services (SLSSs) are a worldwide rapidly growing kind of synchronous social networking services. Most of the SLSSs are highly gamified to increase the users' engagement and to change their behavior, what consequently drives users to continue the usage of a service. This study examined 21 different SLSS websites on what gamification elements are used in each system. A literature review as well as a content analysis were conducted to gather the SLSS websites as well as game elements. Which gamification elements are implemented on social live streaming service websites? And, how many game mechanics can we find on each SLSS? Nearly every SLSS offers the opportunity to follow users and their activities, leaderboards to compare one's ability and performance with other streamers, and gifts to reward others. SLSSs websites with the top browsing location China are the most gamified.
\end{abstract}

\section{Introduction}

A tactical and promising strategy that is used in education, companies, online applications, and many other aspects to engage and motivate people is called "gamification" [1]. The use of gamification asserted itself for increasing peoples' activity and making users continue the usage of a system. It is not only used for motivational aspects, but also for psychological as well as behavioral results. However, even in many research disciplines, respectively system studies, it became a central point of interest [2].

One often applied definition for the term "gamification" is "the use of game design elements in non-game contexts" [3, p. 1] as, for instance, badges or levels. Through these mechanics a user is continuously in contact with one's own accomplishments and achievements. Likewise, users are able to compare their own performance with others (e.g. through leaderboards) [4]. Seaborn and Fels define "gamification" as follows: "the term is used to describe those features of an interactive system that aim to motivate and engage end-users through the use of game design elements and mechanics" [5, p. 14]. This definition refers to the engaging and motivating effect of gamification on users as well.

One kind of social networking service (SNS) that makes use of gamification are social live streaming services (SLSSs). SLSSs users feel rewarded as well as motivated through the interaction with game mechanics [6]. The popularity of these services is growing. Especially in China there are already over 200 different offers of live streaming services [7]. Even popular social media like Facebook and YouTube implemented the function of live streaming to their systems. Streaming live allows broadcasters to interact with their audience in real time. While the broadcaster is performing the live program, viewers are able to communicate with the broadcaster as well as with other viewers via chat [8].

There are three types of SLSSs - general live streaming services, with no specification at all, topicspecific live streaming services with one special interest group dominating the content of the streams, like art or e-sports, and embedded live streaming services, where the function of streaming live was migrated to an existing service (e.g. YouTube Live). Unlike to asynchronous social network services like Facebook or Twitter, social live streaming services are known for being a synchronous service, as everything happens in real time [9].

The users of SLSSs are mostly broadcasting live and chatting with other users or sharing information in their streams. The main motives for using such a service are boredom, socializing, communication, or entertainment [10-13]. In this context, the Uses and Gratifications Theory (UGT) by Blumler and Katz [14] should be mentioned. The use of media is goaldirected as well as guided by certain expectations [15]. Users aim to satisfy their needs and are 
searching for gratifications while using (online) media [16]. McQuail [17] summarizes at least four central motives for media use: entertainment, information, personal identity as well as social interaction. However, following a model about SLSS research, the concept of personal identity should be redefined by the term self-presentation in this context [18]. What's more, the idea of gamification was applied to the model showing the entertaining outcome of game elements on SLSSs users.

Another aspect that deals with the point of human needs and (user) motivation is the Self-Determination Theory (SDT) by Ryan and Deci [19]. Motivation is described as "what 'moves' people to action" [20] and is caused by internal and external aspects. Consequently, one may differentiate between internal as well as external motivation [21]. Intrinsic motivation "involves people freely engaging in activities that they find interesting, that provide novelty and optimal challenge” [22]. And extrinsic motivation "refers to doing something because it leads to separable outcome" [23, p. 54]. Hamari, Koivisto, and Sarsa mention that users of a service are intrinsically motivated through the game design elements [2]. Users will rather recommend an SNS to others if it is gamified, also, their intention to use the service increases [24]. On LinkedIn, for example, we can find a "progress bar for measuring progress in entry of personal details” [25, p. 27], consequently, more users of the service are filling in all personal details.

All in all, gamification is used to design for motivation and to repetitive information system usage [26]. Based on this aspect, the central research question of our investigation is:

RQ1. Which gamification elements are implemented on social live streaming service websites?

\section{Related Work}

Some prior research about the usage of game design elements on live streaming systems was detected. Starting with Wilk, Wulffert, and Effelsberg [27] who developed three different versions (A, B, and $\mathrm{C}$ ) of a live streaming application to test the effect of gamification elements on the broadcasting behavior of SLSSs users. A first version (A) was implemented as base version that did not contain any game mechanics. Version B was constructed like the base version, but additionally the function of leveling was implemented as game mechanic. And finally, the last version (C) of the application had additionally to version $\mathrm{B}$ challenges and badges as features. Then, each version was evaluated by different users. The results for each version are an average time of 125.70 seconds for version $A, 177.90 \mathrm{~s}$ for version $\mathrm{B}$, and for version $\mathrm{C}$ it was 401.98 s. Consequently, the researchers found out that the average streaming time of a user was significantly higher when more game elements were added to the application.

Following, a research about the impact of gamification elements in social live streaming services, having YouNow as a case study, should be mentioned [6]. This study shows to what amount different user groups (producers, participants, and consumers) are motivated as well as rewarded through different gamification elements of the service. However, the study's results show that producers, the streaming and content producing users, are the most rewarded as well as motivated by the gamification elements. Also, the outcomes clarify that every element is at least perceived as neutral but most of them are perceived as highly rewarding and motivating.

Another paper that has YouNow as a case study as well, displays the differences between giving and receiving gratifications in a gamified social live streaming service [28]. The results show if different game design elements are considered as fun, useful, rewarding, and motivating by SLSSs users. Also, the differentiation between getting different gratifications as well as giving different gratifications illustrates that users rate the action of receiving gratifications mostly better than the action of giving.

Likewise, Lu, Xia, Heo, and Wigdor mention the engaging role of the gifting function and fan groups in Chinese SLSSs [7]. Giving streamer a reward is considered as a method of interaction in SLSSs. The usage of gifts is described as similar to emojis. Giftsending viewers are sometimes treated more special by streamers. Some gifts have to be paid with real money, but few users are not able or do not want to spend their money for gifts. Overall, they found out that (in China) gifts display a more meaningful and expressive way of communication than text.

There are some more studies discussing the motivating focus of gamification [29, 30] and the motivation of SLSSs users [31, 32]. All of the studies found out that gamification elements are perceived as rewarding, they engage as well as motivate users, and are changing their behavior. However, no study examined different kinds of SLSSs for what game design elements are implemented.

\section{Methods}

The aim of this study is to get an overview about the implemented game mechanics and game design 
elements on different SLSS websites. On SLSSs, some streamers add their own gamification elements to the layout of their stream via bots (e.g. a ranking that lists top gifting viewers). This kind of game mechanics were not considered in this study. This research only focuses on the game mechanics prepared and applied by the SLSS website itself.

Table 1. SLSSs websites and their global and country-specific rank

\begin{tabular}{l|r|l}
\hline \multicolumn{1}{c|}{ SLSS } & Global Rank & \multicolumn{1}{|c}{$\begin{array}{c}\text { Rank in Top } \\
\text { Country }\end{array}$} \\
\hline YouTube.com & 2 & USA: 2 \\
\hline Facebook.com & 3 & USA: 4 \\
\hline qq.live.com & 8 & China: 2 \\
\hline Twitch.tv & 33 & USA: 14 \\
\hline Nicovideo.jp & 111 & Japan: 9 \\
\hline Panda.tv & 1,903 & China: 133 \\
\hline Pscp.tv & 2,916 & USA: 1,620 \\
\hline yy.com & 4,238 & China: 456 \\
\hline Mixer.com & 4,594 & USA: 1,822 \\
\hline Longzhu.com & 6,448 & China: 662 \\
\hline Ustream.tv & 6,830 & USA: 601 \\
\hline Qiuxiu (x.pps.tv) & 8,646 & China: 1,137 \\
\hline Younow.com & 9,037 & USA: 7,037 \\
\hline Huya.com & 9,980 & China: 585 \\
\hline Kuaishou.com & 10,261 & China: 1,360 \\
\hline Picarto.tv & 10,655 & USA: 3,911 \\
\hline Bigo.tv & 11,120 & Thailand: 706 \\
\hline Chushou.tv & 15,534 & China: 1,960 \\
\hline Yizhibo.com & 18,130 & China: 1,864 \\
\hline Huajiao.com & 19,154 & China: 2,747 \\
\hline Laifeng.com & 42.672 & China: 6,856 \\
\hline Data source: Alexa (as of June 7, 2018) \\
\hline
\end{tabular}

Also, mobile live streaming applications as well as the mobile application of the evaluated platforms were not considered in this research, because only few website services have a mobile application and there are different features and game design elements used in each version. For instance, Instagram's mobile application supports the live function, but the website does not. Consequently, Instagram Live is not a research object of this study.

Furthermore, not every implemented game mechanic of a system may be used by each user group (producer, participant, or consumer). The systems were examined from each user groups perspective, but because of only few differences we showed no differentiation in the results section.

As investigative method, a total of 21 different SLSS websites have been examined and evaluated for a defined set of gamification elements. To this end, we conducted a content analysis with the conventional and deductive approach as literature review [33, 34]. The literature was selected in order to find appropriate SLSSs and game mechanics for our investigation. With the directed approach [33], we examined SLSSs for different game mechanics and categorized them.

\subsection{Appropriate SLSSs}

Primarily, the SLSS websites were selected through literature research [e.g. 7, 35-37] as well as online research. During the online research, we consulted the homepage of the Nanjing Marketing Group, a website specialized on Chinese markets, since China has a big user base for SLSS websites [38]. From this website we got a number of various

Table 2. Common game mechanics on SLSSs

\begin{tabular}{l|l|l}
\hline Game Mechanics & Description & Literature \\
\hline Badges & Visual elements that are awarded for fulfilling tasks & e.g., [39] \\
Capturing Moments & Recording a short clip of a live stream & e.g., [6] \\
Collaboration and Team & Broadcast via split screen of two or more users & e.g., [6] \\
Currency & Collection of different things, e.g. awards or gifts & e.g., [40] \\
$\begin{array}{l}\text { Points } \\
\text { Customization }\end{array}$ & Bought with real money or earned through tasks to buy gifts & e.g., [41] \\
Following Others & Earned through different tasks or site activities & e.g., [42] \\
& Changing features of the channel, profile website, or chat & e.g., [43] \\
Gifts & Users stay up to date through a following, fanning, & \\
Challenges and Goals & subscribing, or befriending function & e.g., [28] \\
Leaderboards & Viewers can show their appreciation with gifts & e.g., [7] \\
& Users can achieve goals and solve tasks that are predefined & \\
Progress Bar & bych platform & e.g., [44] \\
Likes & Statistics of the (daily, weekly, monthly) best streamers & e.g., [42] \\
Levels & according to different criteria & e.g., [45] \\
\hline
\end{tabular}


SLSS websites which we visited. Some websites were not accessible and the remaining amount was too big, so we decided to get their websites ranking position in China from Alexa and took the 11 best websites. Also, we searched for the phrase "live stream" or hashtag "\#livestream” on social media (e.g. Instagram, YouTube, Facebook, and Twitter) and got the remaining Western SLSS websites.

After gathering the SLSSs, we checked their Alexa Ranking compared to other websites of the world as well as their position in the country with the most users (Table 1). The table displays all relevant SLSSs for our investigation which were examined for the implemented game mechanics.

\subsection{Game Mechanics}

The game mechanics were selected through different theoretical backgrounds. Especially previous literature reviews about gamification (e.g. [2]) and researches about gathering different game mechanics (e.g. [44, 46-47]) have been considered. Afterwards, we had a list of over 20 assorted gamification elements. Following, the conventional approach via observing SLSSs was applied to get an impression about what game mechanics are implemented on SLSSs. Those game elements we could not identify on SLSS websites were withdrawn from the prepared list and one game mechanic that was not mentioned as gamification in the considered literature was added (capturing moments). The remaining 14 game design elements and a short definition of each one are listed in table 2.

\subsection{The Examination}

A pair of two researchers, following the four eyes principle [48], has examined each live streaming website. They discussed every game mechanic presented on the website and always reached a conclusion on which category was appropriate for the corresponding game mechanic that was observed. For example, if some form of money exchange could be recognized on the SLSS, it was classified as the 'currency' category.

Since the two researches did not have the appropriate language skills for the Chinese or Japanese SLSSs, a Chinese native speaker who acted as a translator was present for all investigation sessions on the Chinese SLSSs, and a fluent speaker in Japanese for the investigation of the Japanese website. All in all, we could identify fourteen different game mechanics that are applied by different SLSSs (Table 2).

\section{Results}

What game mechanics are applied by which service? Differences can be observed when looking at the distribution of the total number of game mechanics among SLSS websites (Table 3). Especially China's SLSSs display a high number of game design elements. Eight of the eleven observed Chinese SLSS websites have ten or more implemented game elements. Also, the most game mechanics overall (twelve) can be found on SLSSs in China, namely Huya and Longzhu. Contrary, the number differs widely for the SLSSs that are the most popular in the U.S. The social media services which embedded the function of live streaming to the system (YouTube and Facebook) only have three implemented gamification elements, and, Ustream the service for professional (business) streaming, even has none. The most game mechanics for U.S. systems have been found on the general SLSS YouNow, with 11 applied game mechanics. The gaming-focused SLSSs Twitch and Mixer implement a high number of game elements as well (nine and eight respectively).

Table 3. No. of game mechanics per SLSS ( $N=14)$

\begin{tabular}{|c|c|}
\hline $\begin{array}{l}\text { SLSSs ordered by No. of } \\
\text { Game Mechanics and } \\
\text { Country’s Ranking }\end{array}$ & $\begin{array}{l}\text { No. of Game } \\
\text { Mechanic } \\
\text { Elements }\end{array}$ \\
\hline \multicolumn{2}{|l|}{ China } \\
\hline Huya.com (585) & 12 \\
\hline Longzhu.com (662) & 12 \\
\hline qq.live.com (2) & 11 \\
\hline Panda.tv (133) & 11 \\
\hline yy.com (456) & 11 \\
\hline Laifeng.com $(6,856)$ & 11 \\
\hline Qiuxiu (x.pps.tv) $(1,137)$ & 10 \\
\hline Yizhibo.com $(1,864)$ & 10 \\
\hline Chushou.tv $(1,960)$ & 9 \\
\hline Huajiao.com $(2,747)$ & 8 \\
\hline Kuaishou.com $(1,360)$ & 5 \\
\hline \multicolumn{2}{|l|}{ Japan } \\
\hline Nicovideo.jp (9) & 6 \\
\hline \multicolumn{2}{|l|}{ Thailand } \\
\hline Bigo.tv (706) & 6 \\
\hline \multicolumn{2}{|l|}{ U.S. } \\
\hline YouNow.com $(7,037)$ & 11 \\
\hline Twitch.tv (14) & 9 \\
\hline Mixer.com $(1,822)$ & 8 \\
\hline Periscope.tv $(1,620)$ & 5 \\
\hline Picarto.tv $(3,911)$ & 3 \\
\hline YouTube.com (2) & 3 \\
\hline Facebook.com (4) & 3 \\
\hline Ustream.tv (601) & 0 \\
\hline
\end{tabular}




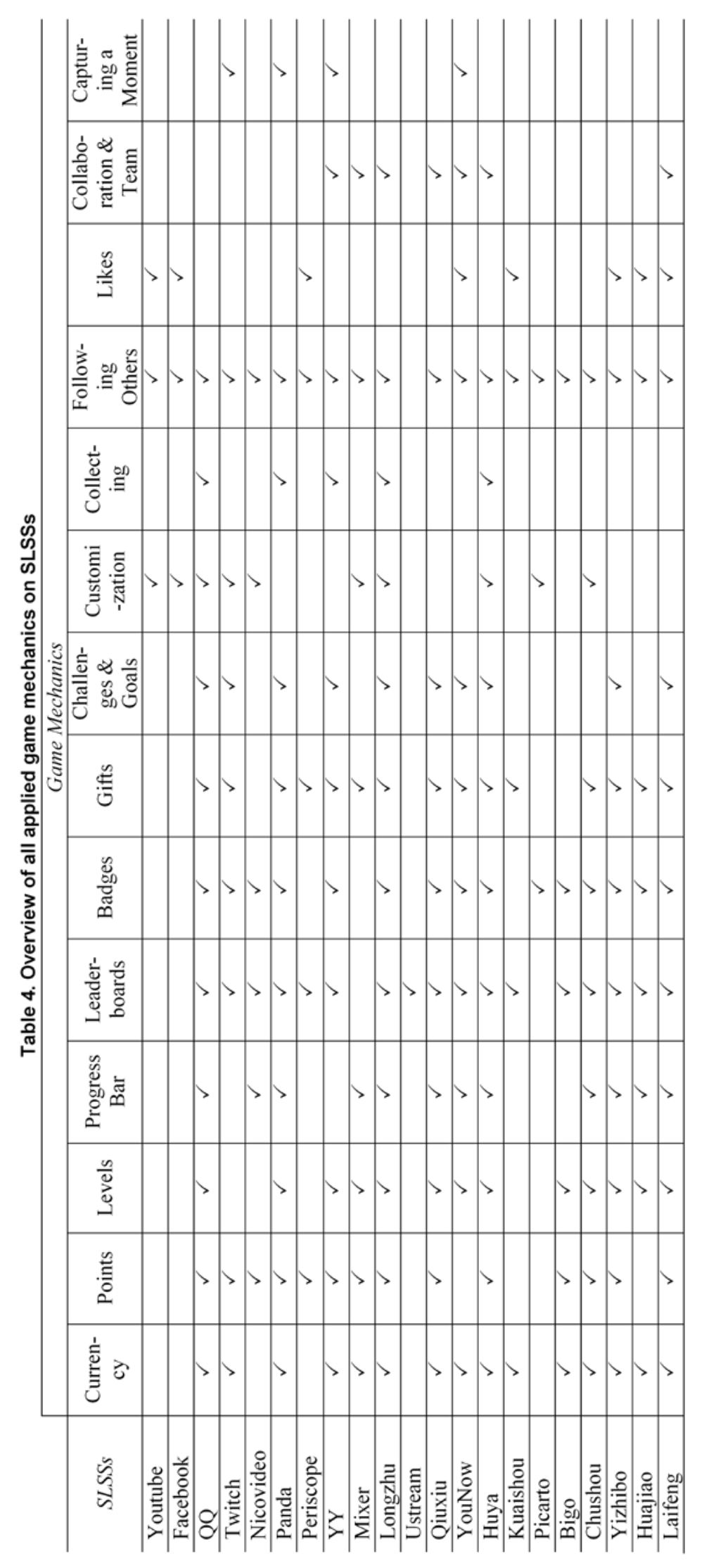


On the Japanese (Nicovideo) and Thai (Bigo) SLSS websites we identify six game design elements. Also, in Asia, we find the option to connect with others, use currency, buy gifts, and the displaying of the most successful streamers via leaderboards on every observed SLSSs (Table 4). All SLSSs implemented the option to connect with other users via following or befriending them, except for Ustream.

Table 5. Number of SLSS websites having game elements $(\mathrm{N}=21)$

\begin{tabular}{l|c}
\hline $\begin{array}{l}\text { Game Design Element } \\
\text { Ordered by Frequency }\end{array}$ & $\begin{array}{c}\text { No. of SLSSs } \\
\text { having the Game } \\
\text { Mechanic }\end{array}$ \\
\hline Following Others & 20 \\
\hline Leaderboards & 16 \\
\hline $\begin{array}{l}\text { Currency } \\
\text { Badges } \\
\text { Gifts }\end{array}$ & 15 \\
\hline Points & 14 \\
\hline Levels & 13 \\
\hline Progress Bar & 12 \\
\hline Challenges \& Goals & 10 \\
\hline Customization & 10 \\
\hline Collaboration \& Team & 7 \\
\hline Likes & 6 \\
\hline Collecting & 5 \\
\hline Capturing a Moment & 4 \\
\hline
\end{tabular}

It is important to keep in mind that YouTube and Facebook are already established websites that do not have to compete with newer services as much, which could be a reason why they do not implement as many game mechanics, since they already have a big user base. It has to be mentioned that Ustream as well as Periscope value a more serious approach to live streaming, as Ustream wants to focus on education and business communication, and Periscope on reporting on live events for citizen journalism.

To conclude, Asia seems to focus on a high degree of gameful designs on their SLSS websites in contrast to the U.S.

In table 5 the amount of SLSS websites having the respective gamification element is displayed. The most represented game design element on the examined SLSS websites is the function of following other users - respectively becoming a fan or subscriber. This function could be found on 20 of 21 SLSS websites. Furthermore, occurring on 16 SLSSs, leaderboards are the second most feature. Coins, badges as well as gifts are implemented on 15 streaming websites, each. Next, points are on 14, levels are on 13, and progress bars are on 12 out of 21 SLSS websites. On 10 different streaming systems, challenges or goals are found. The function of customization is implemented on 10 of the examined websites as well. Collaboration is used on 7 SLSSs websites and likes, or the possibility of social feedback, on 6 SLSSs. Collecting things was found on 5 systems. The least used element is the function of capturing a moment of a stream. It was only found on 4 out of 21 SLSS websites. Importantly, on some systems users have the opportunity to re-watch a stream as a video, therefore it is not necessarily needed or that meaningful on each service.

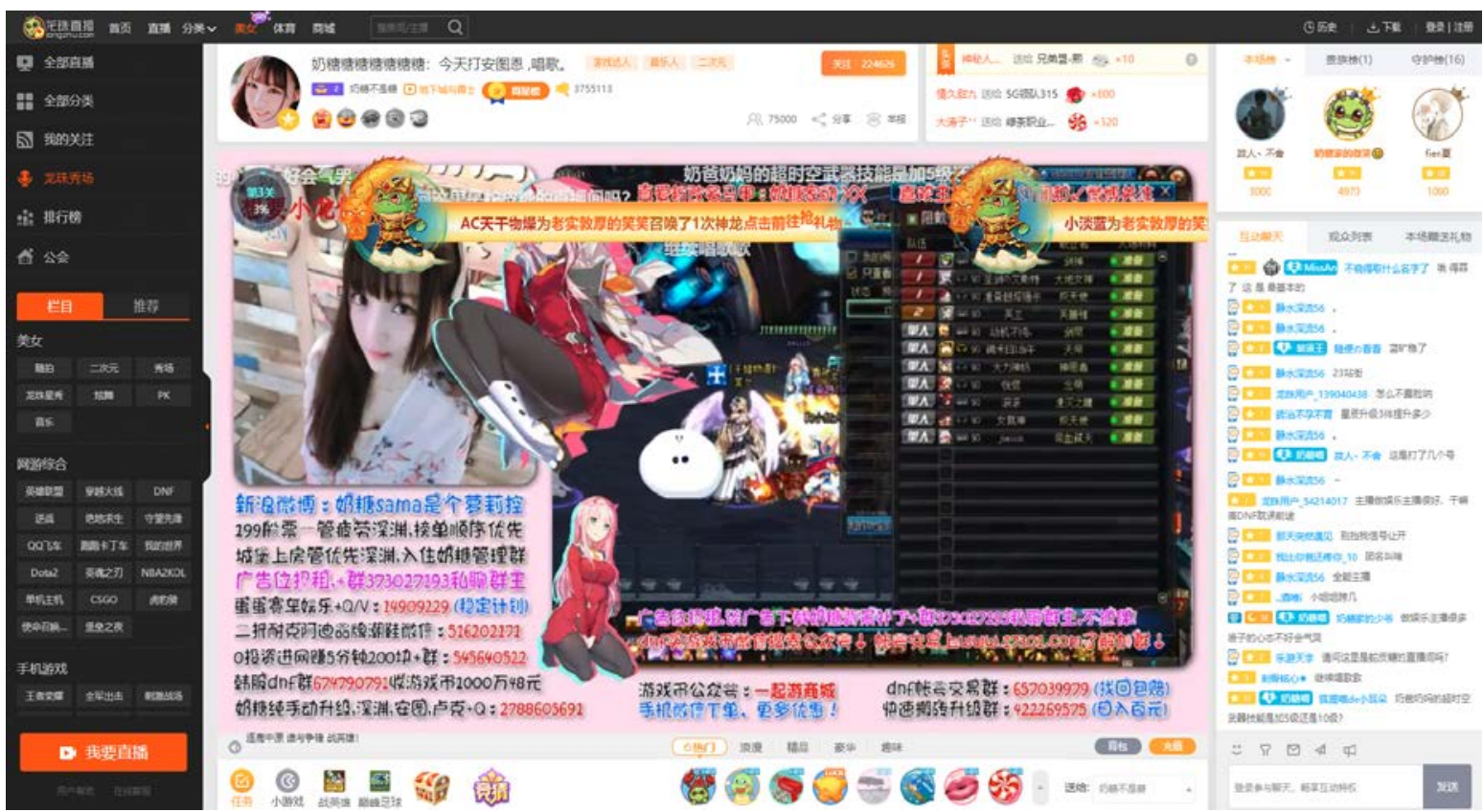

Figure 1. Screenshot of one of the SLSS websites with the most gamification elements (Longzhu.com) 


\section{Discussion}

To investigate what gamification elements are implemented, and, on which social live streaming service, we applied a content analysis by using the conventional and directed approach. This way we determined 14 different game mechanics and 21 SLSSs around the world, eleven popular in China, eight in the U.S., and one each in Thailand and Japan. We even examined two of the SLSSs in the top three of the most visited websites in the world (YouTube and Facebook). We found nine services that apply ten or more game elements that we determined, eight of them are popular in China. The most used game mechanics can be found on Huya and Longzhu with 12 applied elements.

The game mechanic that was used the most often (20 times) is "following others", which has a social aspect for the users. This facet was applied by all SLSSs in Asia and in the U.S., except Ustream. Eight of the eleven Chinese SLSSs have ten or more game design elements, for the U.S. SLSSs only one of the eight observed systems has ten or more game mechanics.

Our study found that gamification is a big deal in Chinese SLSSs. We are formulating a hypothesis because gamification is not studied explicitly in China and the U.S: If we look at the mean of the implemented game mechanics per most visited region, it is 5,375 (43/8) for U.S. systems and 10 (110/11) for Chinese systems. Following Hofstede [49] the culture in China is pragmatic (score of 87). Consequently, the preferable use of an easy and gamified system is expectable. "Gamification features are perceived to be more important by users whose goals are easy, outcome-focused and who are more inclined towards providing themselves to others" [30, p. 67]. U.S. citizens are not that pragmatic (score of 26). Also, Hofstede mentions that the Chinese society is "driven by competition, achievement and success" [49], which are all indicators and characteristics of gamification.

Furthermore, gamification is considered as group orientated as there are, for instance, giving and taking gifts as well as spending virtual currencies. In contrast to the self-orientated culture in the U.S., in China group orientation and personal relationships dominate the cultural behavior (see [49]). Nowadays one can find a lot of gamification elements in Chinese everyday life. Schools successfully implemented gamification elements for teaching, and colleges are supposed to follow [50]. China will even apply a "social credit" which aims to score the trust level of citizens which is composed of, e.g. professional conduct and tax evasion [51].
To get an idea of the implemented gamification elements on SLSSs and what is the goal of each game mechanic, following, the examined elements are described in more detail and some examples of game mechanics on SLSS websites are given. Badges are visual elements which can be earned through fulfilling certain conditions [39]. Zichermann and Cunningham say that they are used "to encourage social promotion" and "mark the completion of goals” [4, p. 55]. On YouNow, for example, there are several badges for displaying different experience ranges of broadcasters.

The function of capturing a moment is not described in further literature because it is a special SLSSs' function and SLSSs are rather new. It was considered as gamification element because of the aspect of being the creator of a short clip. In SLSSs viewers are able to capture the last few, mostly 15, seconds of a live stream. Afterwards, the clip is shown on the profile of the broadcaster as well as of the capturing user.

Collaboration and teams are helpful for the social aspect in games. In game play teams are "working together and achieving a goal” [52, p. 32]. On SLSSs broadcasters are streaming together for socializing and they may reach a wider audience together.

Collecting is an activity that most people enjoy. The aim of a collection is to complete sets. Some are comparing their own collections and are trading [40]. Respectively, on QQ Live, a user has its own backpack to collect different gifts.

Points are a unit that increases by accomplishing particular actions and certain site-activities [42]. They motivate users through feedback function as well as trough collecting more points [40].

Virtual currencies are like points, but through them one is able to buy virtual goods [41] and, on SLSSs, gifts. In many SLSSs, especially in Chinese services, virtual currencies have to be paid with real money. The SLSS website yy.com has red diamonds as currency, QQ Live has eggs, and huya.com offers golden and silver beans as payment method.

Customization allows users to change features, respectively the design of their profile website. On Twitch users are able to change the color of their name which is displayed in the chatting box.

Connecting with others via following the user is a basic human need, because people want to feel connected with others. But also, others want to lead people, since there cannot be leaders without followers [53]. With the usage of SLSSs users on both ends can hold this special kind of connection.

Gifts are a virtual form of appreciation. They can vary in value, some are easy to buy, but some are more expensive, making them even more valuable to 
the receiver [54]. Gifts can have all kinds of forms, on Longzhu.com we can find kisses and candies (Figure 1), but on Yizhibo we find virtual flower petals or cars, for example.

Challenges and Goals are little tasks that users can complete on SLSSs [44] This way the user gets motivated to interact on the SLSS, and challenge himself to complete goals and make him feel that he has earned his achievement. An example for a goal is, to reach a certain number of viewers for a stream.

Leaderboards are lists of players, who are ranked based on different criteria of their success [39, 42]. This way, the user is motivated to accomplish a higher ranking on the SLSS, which also creates social impulses [4]. On Panda.tv for example we find rankings of the users with the most received comments, who received or gave the most money, who has had the most viewers and so on. On Twitch, one can find rankings of stream specific donors.

The progress bar acts as feedback function for users [46, 40]. This way he can observe how many points he needs to progress to the next level, encouraging him to take the next step [40].

Likes are a form of approval that users signal the streamer. This helps the user to feel appreciated by the viewers [46]. Likes are implemented on a lot of SNSs, like Facebook for example, but can be found on SLSSs as well, like Periscope.

Levels represent the player's experience on the SLSSs [4, 39], which leads the player to a feeling of mastery and accomplishment by achieving higher levels [52]. An example for levels can be found on YouNow, where one's level rises by fulfilling different site activities, for instance when the streamer is broadcasting live.

But, what strikes, compared to other types of SNSs, SLSSs make use of a greater variety of game design elements. Only few game mechanics like avatars, story and narrative elements, or quests were not implemented by the observed SLSSs, probably because they will not fit the structure of such services. However, removing gamification from an SNS reduces the overall participation of users [55].

Coming back to the outcomes of the study, capturing moments, collecting of virtual items and likes were the least implemented among the SLSSs. In the U.S., we find YouNow with the most gamified elements (11), and the two game-focused SLSSs Twitch (9) and Mixer (8). Here, we also find the lowest numbers of game mechanics: Picarto has 3, YouTube Live and Facebook Live only have 3 each as well and Ustream even has none.

Since Facebook and YouTube are already the most popular social media on the web which implemented the function of SLSSs, they probably do not feel the need to implement as many game mechanics to motivate the users to use their service, since they already have an established user base. Furthermore, Ustream and Periscope have a more serious focus in SLSSs, namely education and live news. It is interesting to discuss why some game elements might be more often implemented than others. Gamification elements have different psychological effects. Badges and leaderboards positively affect competence need satisfaction [45]. Our results show that those are the game mechanics that were implemented the most often, especially on all Chinese SLSSs. Also, the main game mechanics that were implemented the most are also supporting social interactions (following others) and the selfpresentation of a user (leaderboards, badges).

Overall, we could observe that the SLSSs in Asia focus more on the number of gamified elements than those that are popular in the U.S.

\section{Limitations and outlook}

Some limitations of this study were recognized and need to be acknowledged. Since just in China are already over 200 different systems for streaming live [7], there is a large remaining number of SLSSs which were not considered in this paper. From the unidentified great amount of SLSSs we observed only a limited number, to be more accurate, 21. Furthermore, live streaming systems from South America, the Middle East, Africa, or other countries were not detected. Although we followed the foureyes principle there might be some other game mechanics which were not identified. Also, our study has no further statistical results, like correlations or significance test. Interviews with some developers of live streaming platforms will provide a better and more obvious insight into the background thoughts and goals of using game elements on each platform.

Further research should concentrate on a more detailed overview about the differences between Chinese as well as U.S. American SLSSs and, additionally, on the country-specific varieties of used game mechanics. Also, the observation of mobile social live streaming application and the comparison of websites as well as mobile applications will be interesting. Finally, it is important to note that no other kind of social media implements such a wide array of game elements in contrast to SLSSs. A comparison of all types of social networking services and their implemented gamification elements should be made.

This research presents a detailed overview about the gamification elements that are used on different 
SLSSs websites. It creates a reasonable basis for further studies about live streaming as well as designing systems with gamification.

\section{References}

[1] S. Deterding, D. Dixon, R. Khaled, and L. Nacke, "From game design elements to gamefulness: defining gamification", In Proceedings of the 15th International Academic MindTrek Conference: Envisioning Future Media Environments (September 28-30), 2011, pp. 9-15.

[2] J. Hamari, J. Koivisto, and H. Sarsa, "Does gamification work? A literature review of empirical studies on gamification", in Proceedings of the $47^{\text {th }}$ Hawaii International Conference on System Sciences (January 69), IEEE Computer Society, Washington D.C., 2014, pp. 3025-3034.

[3] S. Deterding, L.E. Nacke, and D. Dixon, "Gamification: toward a definition", in Proceedings of the $29^{\text {th }} \mathrm{CHI}$ Conference on Human Factors in Computing Systems (May 7-12), ACM, New York, NY, 2011, pp. 1-4.

[4] Zichermann, G., and C. Cunningham, Gamification by design: Implementing game mechanics in web and mobile apps, O'Reilly Media, Sebastopol, CA, 2011.

[5] K. Seaborn, and D. Fels, "Gamification in theory and action”, International Journal of Human-Computer Studies, 74(C), 2015, pp. 14-31.

[6] K. Scheibe, "The impact of gamification in social live streaming services", in Proceedings of the HCI International 2018 Conference on Human Computer Interaction (July 15-20), Springer International, Cham, Switzerland, 2018, pp. 99-113.

[7] Z. Lu, H. Xia, S. Heo, and D. Wigor, "You watch, you give, and you engage: A study of live streaming practices in china”, in Proceedings of the 2018 CHI Conference on Human Factors in Computing Systems (April 21-26), ACM, New York, NY, 2018, pp. 1-13.

[8] M.B. Friedländer, "And action! Live in front of the camera: An evaluation of the social live streaming service YouNow”, International Journal of Information Communication Technologies and Human Development, 9(1), 2017, pp. 15-33.

[9] K. Scheibe, K.J. Fietkiewicz, and W.G. Stock, "Information behavior on social live streaming services", Journal of Information Science Theory and Practice, 4(2), 2016, pp. 6-20.

[10] D. Gros, B. Wanner, A. Hackenholt, A., P. Zawadzki, and K. Knautz, "World of streaming, motivation and gratification on Twitch", in Proceedings of the HCI International 2017 Conference on Human Computer Interaction (July 9-14), Springer, Cham, Switzerland, 2017, pp. 44-57.

[11] Z. Hilvert-Bruce, J.T. Neill, M. Sjöblom, and J. Hamari, "Social motivations of live-streaming viewer engagement on twitch", Computers in Human Behavior, 84, 2018, pp. 58-67.

[12] M.B. Friedländer, "Streamer motives and usergenerated content on social live-streaming services", Journal of Information Science Theory and Practice, 5(1), 2017, pp. 65-84.
[13] C. Chen and Y. Lin, "What drives live-stream usage intention? The perspective of flow, entertainment, social interaction and endorsement", Telematics and Informatics, 35, 2018, pp. 293-303

[14] Blumler, J.G., and E. Katz, The uses of mass communications: Current perspectives on gratifications research, Sage, Newbury Park, CA, 1974.

[15] E. Katz, J.G. Blumler, and M. Gurevitch, "Utilization of mass communication by the individual", in The uses of mass communications: Current perspectives on gratification research, J.G. Blumler, and E. Katz (eds.), 1974, Sage, Beverly Hills, California, pp. 19-31.

[16] D. McQuail, J.G. Blumler, and J. Brown, "The television audience: A revised perspective", in Sociology of mass communication, D. McQuail (ed.), 1972, Penguin, Middlesex, England, pp. 135-165.

[17] McQuail, D., Mass communication theory, Sage, London, UK, 1983.

[18] F. Zimmer, K. Scheibe, and W.G. Stock, “A model for information behavior research on social live streaming services (SLSSs)", in Proceedings of the HCI International 2018 Conference on Human Computer Interaction (July 15-20), Springer International, Cham, Switzerland, 2018, pp. 429-448.

[19] R.M., Ryan, and E.L. Deci, "Self-determination theory and the facilitation of intrinsic motivation, social development, and well-being”, American Psychology, 55(1), 2000, pp. 68-78.

[20] Ryan, R.M., and Deci, E.L., Self-determination theory. Basic psychological needs in motivation, development, and wellness, Guilford Press, New York, NY, London, UK, 2017.

[21] R.M. Ryan, and E.L. Deci, "Intrinsic and extrinsic motivations: Classic definitions and new directions", Contemporary Educational Psychology, 25, 2000, pp. 5467.

[22] E.L Deci, and R.M. Ryan, "The "what" and "why" of goal pursuits: Human needs and the self-determination of behavior", Psychological Inquiry, 11(4), 2000, pp. 227268.

[23] M.R. Ryan, and E.L. Deci, "Intrinsic and extrinsic motivations: Classic definitions and new directions", Contemporary Educational Psychology, 25(1), 2000, pp. 54-67.

[24] J. Hamari, and J. Koivisto, "Social motivations to use gamification: An empirical study of gamifying exercise”, In Proceedings of the $21^{\text {st }}$ European Conference on Information Systems (June 5-8), Utrecht, The Netherlands, 2013.

[25] K. Huotari, and J. Hamari, "A definition for gamification: Anchoring gamification in the service marketing literature”, Electronic Markets, 27, 2017, pp. 2131

[26] S. Deterding, "Gamification: Designing for motivation”, Interactions, 19(4), 2012, pp. 14-17.

[27] S. Wilk, D. Wulffert, and W. Effelsberg, "On influencing mobile live video broadcasting users", in Proceedings of the IEEE International Symposium on Multimedia (December 14-16), IEEE Computer Society, Washington, D.C., 2015. 
[28] K. Scheibe, C. Meschede, J. Göretz, and W.G. Stock, Giving and Taking Gratifications in a Gamified Social Live Streaming Service. In Proceedings of the 5th European Conference on Social Media (June 21-2), Academic Conferences and Publishing Limited, Reading, UK, 2018, pp. 264-273.

[29] J. Koivisto, and J. Hamari, "Demographic differences in perceived benefits from gamification”, Computers in Human Behavior, 35, 2014, pp. 179-188

[30] J. Hamari, L. Hassan, and A. Dias, "Gamification, quantified-self or social networking? Matching users' goals with motivational technology”, User Modeling and UserAdapted Interaction, 28(1), 2018, pp. 35-74.

[31] J. Hamari, and M. Sjöblom, "What is eSports and why do people watch it?”, Internet Research, 27(2), 2017, pp. 211-232.

[32] M. Sjölblom, and J. Hamari, "Why do people watch others play video games? An empirical study on the motivation of Twitch users", Computers in Human Behavior, 75, 2017, pp. 985-996.

[33] H.-F. Hsieh, and S.E. Shannon, "Three approaches to qualitative content analysis”, Qualitative Health Research, 15(9), 2005, pp. 1277-1288.

[34] S. Elo, and H. Kyngäs, "The qualitative content analysis”, Journal of Advanced Nursing, 62(1), 2008, pp. 107-115.

[35] T. Izumi, H. Tarumi, E. Kagawa, and R. Yaegashi, "An experimental live streaming of an ice hockey game with enhancement of mutual awareness", in Proceedings of the 6th International Conference on Collaboration Technologies (August 29-31), Information Processing Society, Hokkaido, Japan, 2012, pp. 22-25.

[36] F. Zimmer, K.J. Fietkiewicz, and W.G. Stock, "Law infringements in social live streaming services", in Proceedings of the HCI International 2017 Conference on Human Computer Interaction (July 15-20), Springer, Cham, Switzerland, 2017, pp. 567-585.

[37] K. Pires, and G. Simon, "YouTube live and Twitch: A tour of user-generated live streaming systems", in Proceedings of the 6th ACM Multimedia Systems Conference (March 18-20), ACM, New York, 2015, pp. 225-230.

[38] W. Marszalek, Introduction to live-streaming in China, 2018, Online: https://www.nanjingmarketing group.com/ blog/live-streaming-china.

[39] J. Hamari, "Do badges increase user activity? A field experiment on effects of gamification?", Computers in Human Behavior, 71, 2017 pp. 469-478.

[40] J. Kumar, and M. Herger, Gamification at work: Designing engaging business software, Springer, Berlin, Heidelberg, 2013.

[41] D. Dicheva, C. Dichev, G. Agrev, and G. Angelova, "Gamification in education: A systematic mapping study", Educational Technology \& Society, 18(3), 2015, pp. 75-88.

[42] M. Sailer, J.U. Hense, H. Mandl, and M. Klevers, "Psychological perspectives on motivation through gamification”, Interaction Design and Architecure(s) Journal, 19, 2013, pp. 28-37.

[43] D. Strmecki, A. Bernik, and D. Radosevic, "Gamification in e-learning: Introducing gamified design elements into e-learning systems”, Journal of Computer Sciences, 11(12); 2015, pp. 1108-1117.

[44] S. Thiebes, S. Lins, and D. Basten, "Gamifying information systems: A synthesis of gamification mechanics and dynamics", in Proceedings of the $22^{\text {nd }}$ European Conference on Information Systems (June 9-11), Association for Information Systems, Atlanta, 2014, pp. 117

[45] M. Sailer, J.U. Hense, S.K. Mayr, and H. Mandl, "How gamification motivates: An experimental study of the effects of specific game design elements on psychological need satisfaction", Computers in Human Behavior, 69, 2017, pp. 371-380.

[46] A. Matallaoui, J. Koivisto, J. Hamari, and R. Zarnekow, “How effective is 'exergamification'? A systematic review on the effectiveness of gamification features in exergames", in Proceedings of the $50^{\text {th }}$ Hawaii International Conference on System Sciences (January 47), IEEE Computer Society, Washington, D.C., 2017, pp. 3316-3325.

[47] T. Wolf, W.H., Weiger, and M. Hammerschmidt, "Gamified digital services: How gameful experiences drive continued service usage", in Proceedings of the $51^{\text {st }}$ Hawaii International Conference on System Sciences (January 36), IEEE Society, Washington, D.C., 2018, pp. 1187-1196.

[48] Y. Nihei, M. Terashima, I. Suzuki, and S. Morikawa, „Why are four eyes better than two? Effects of collaboration on the detection of errors in proofreading", Japanese Psychological Research, 44(2), 2002, pp. 173179.

[49] Hofstede Insights, https://www.hofstedeinsights.com/country-comparison/china,the-usa/ Retrieved: September 4, 2018.

[50] Z. Ramdan, "The gamification of trust: the case of Chinas's 'social credit'”, Marketing Intelligence \& Planning, 36(1), 2018, pp. 93-107.

[51] F. Wang, Y. Wang, and X. Hu, "Gamification Teaching Reform for Higher Vocational Education in China: A Case Study on Layout and Management of Distribution Center", International Journal of Emerging Technologies in Learning, 12(9), 2017, pp. 130-144.

[52] Kapp, K.M. The gamification of learning and instruction: Game-based methods and strategies for training and education, Pfeiffer \& Company, San Francisco, CA, 2012.

[53] P. Weiser, D. Bucher, F. Cellina, and V. De Luca, “A taxonomy of motivational affordances for meaningful gamified and persuasive technologies", in Proceedings of the $29^{\text {th }}$ EnviroInfo and $3^{\text {rd }}$ ICT for Sustainability (September 7-9), Atlantis Press, Penryn Cornwall, United Kingdom, 2015, pp. 1-10.

[54] S.H. Hsu, J.W. Wang, and C.C. Lee, "Designing attractive gamification features for collaborative storytelling websites”, Cyberpsychology, Behavior, and Social Networking, 16(6), 2013, pp. 428-435.

[55] J. Thom, D. R. Millen, and J. DiMicco, "Removing gamification from an enterprise SNS”, In Proceedings of the ACM 2012 Conference on Computer Supported Cooperative Work (February 11-15), Seattle, Washington, 2012. 